\title{
PERANCANGAN SISTEM PENGENDALIAN INTERNAL PERSEDIAAN BARANG GUEST SUPPLIES PADA DEPARTMENT HOUSEKEEPING DI HOTEL XYZ
}

\author{
Tiara Ratna Biandari \\ Universitas Trilogi \\ tiararatnabiandari@yahoo.co.id \\ Ludwina Harahap \\ Universitas Trilogi \\ ludyhara@trilogi.ac.id
}

\begin{abstract}
To provide good service, XYZ Hotel, which has been established since 2010, must pay attention to all things related to guest services, one of which is the management of guest supplies in order for guest equipment management to run properly and reduce risks that may arise, internal control practices are needed. This research is a case study where this research will help in overcoming internal control problems that exist in guest supplies. Data collection was carried out by interview and documentation methods. Furthermore, data analysis and evaluation will be carried out which will produce a recommendation for improvement, namely the design of an internal control system based on COSO. This improvement is intended so that the activity of managing guest supplies at XYZ Hotels can be more effective and efficient in its implementation.
\end{abstract}

Keywords: Internal Control, Inventory, Hotel, Guest Supplies, Design.

\section{PENDAHULUAN}

Hotel XYZ merupakan hotel bintang dua yang berlokasi di daerah Blok $\mathrm{M}$ Jakarta Selatan. Sebagai hotel yang berdiri di tengah kota, Hotel XYZ memiliki pesaing - pesaing yang kompetitif. Dengan persaingan yang kompetitif dengan hotel hotel di sekitar, maka Hotel XYZ harus dapat meningkatkan pelayanannya agar tamu yang menginap memiliki pengalaman menginap yang positif. Untuk memberikan pelayanan yang baik, maka Hotel XYZ harus memperhatikan segala hal yang berhubungan dengan pelayanan tamu, salah satunya yaitu dengan pengelolaan persediaan guest supplies.

Menurut Larasati (2017) Guest supplies adalah barang persediaan yang bisa digunakan untuk tamu. Guest supplies ini merupakan perlengkapan yang dibutuhkan oleh para tamu hotel dan dikelola oleh housekeeping department. Oleh karena itu pengendalian guest supplies ini harus dilakukan secara baik dan rutin agar pelayanan yang diberikan kepada tamu dapat berjalan dengan optimal.

Menurut Hartoni (2015: 14) Housekeeping department, bagi sebagian besar hotel, merupakan sumber pendapatan yang paling besar, karena tamu yang menginap tentu mengeluarkan uang yang banyak untuk sewa bila dibandingkan dengan uang yang harus dibayarkannya untuk makan dan minum serta pengeluaran yang lain. Berikut adalah data pendapatan perminggu dari bulan Januari s.d. Oktober 2020: 
Tiara Ratna Biandari, Ludwina Harahap/ Perancangan Sistem Pengendalian Internal Persediaan Barang Guest Supplies Pada Department Housekeeping Di Hotel XYZ

Tabel 1 Data Penerimaan Mingguan

\begin{tabular}{|c|c|c|c|c|c|c|}
\hline \multirow{2}{*}{ BULAN } & \multicolumn{5}{|c|}{ PENDAPATAN ROOM / MINGGU } & \multirow{2}{*}{ TOTAL } \\
\hline & MINGGU 1 & MINGGU 2 & MINGGU 3 & MINGGU 4 & MINGGU 5 & \\
\hline JAN & $4,997,003$ & $22,421,094$ & $24,272,702$ & $14,670,844$ & $45,712,574$ & $112,074,217$ \\
\hline FEB & - & $24,968,705$ & $31,326,908$ & $38,374,694$ & $40,599,194$ & $135,269,501$ \\
\hline MAR & $22,803,862$ & $12,551,717$ & $13,955,908$ & $5,730,079$ & $3,575,680$ & $58,617,246$ \\
\hline APR & - & - & - & - & - & - \\
\hline MEI & - & - & - & - & & - \\
\hline JUN & - & - & - & 250,000 & $2,148,760$ & $2,398,760$ \\
\hline JUL & $11,138,645$ & $18,978,414$ & $13,007,215$ & $18,631,564$ & $9,661,899$ & $71,417,737$ \\
\hline $\mathrm{AGU}$ & $8,660,068$ & $15,064,635$ & $21,067,764$ & $12,916,192$ & $15,247,465$ & $72,956,124$ \\
\hline SEP & $14,270,174$ & $9,245,578$ & $9,623,500$ & $12,047,548$ & $5,298,351$ & $50,485,151$ \\
\hline $\mathrm{OKT}$ & $12,421,330$ & $20,865,981$ & $17,714,530$ & $19,812,718$ & $20,604,058$ & $91,418,617$ \\
\hline TOTAL & $74,291,082$ & $124,096,124$ & $130,968,527$ & $122,433,639$ & $142,847,981$ & $594,637,353$ \\
\hline
\end{tabular}

Sumber: City Ledger Hotel XYZ, 2020. Data diolah.

Seperti yang dapat dilihat dari tabel 1.1.1 yaitu data penerimaan yang di dapat dari penjualan kamar, maka demi kelancaran penyiapan dan pemeliharaan kebersihan kamar yang ditentukan oleh housekeeping sebagai sumber pendapatan, berarti juga bahwa pengelolaan persediaan guest supplies juga harus diperhatikan dengan baik karena guest supplies merupakan barang persediaan yang berkaitan langsung dengan tamu.

Hotel XYZ harus memiliki pengorganisasian yang baik agar dapat mengelola aktivitas perusahaan sedemikian rupa yang pada akhirnya tercipta pengendalian yang memadai dalam mempertahankan kelangsungan hidup hotel. Sistem pengendalian internal merupakan hal yang penting, agar:

1. Harta kekayaan perusahaan aman,

2. Laporan keuangan akurat dan andal,

3. Kegiatan operasional menjadi efisien dan efektif, serta

4. Meminimalisasi resiko yang akan terjadi ataupun fraud.

Berdasarkan hal itu, maka tujuan utama dari adanya sistem pengendalian internal untuk persediaan guest supplies di Hotel XYZ ini adalah:
1. Melindungi persediaan dari kerusakan/pencurian,

2. Laporan keuangan dilaporkan dengan benar,

3. Mencegah pemesanan dalam jumlah berlebihan maupun kekurangan stok,

4. Budget tidak terganggu karena pemesanan barang yang mendadak,

5. Menghindari komplainan tamu sehingga experience review di forum online tetap baik dan nama baik hotel tidak tercoreng.

Pengendalian internal yang lemah dapat menyebabkan tidak dapat terdeteksinya kecurangan ataupun ketidakakuratan dalam pencatatan proses akuntansinya sehingga laporan akuntansi menjadi kurang dapat dipercaya. Menurut COSO (Committee of Sponsoring Organization of The Treadway Commission) sistem pengendalian internal merupakan suatu proses yang melibatkan dewan komisaris, manajemen, dan personil lain, yang dirancang untuk memberikan keyakinan memadai tentang pencapaian tiga tujuan berikut ini, yaitu:

- Efektivitas dan efisiensi operasi,

- Keandalan pelaporan keuangan, 
- Kepatuhan terhadap hukum dan peraturan yang berlaku.

Persediaan guest supplies merupakan salah satu aktiva perusahaan di dalam hotel yang besar resikonya terhadap fraud, contohnya adalah sebagai berikut:

1. Mark up harga saat pembelian,

2. Penggunaan barang guest supplies secara berlebihan ataupun penggunaan yang tidak diperuntukan penggunaannya,

3. Dapat terjadi pencurian yang tidak bisa dilacak apabila tidak ada pencatatan secara berkala.

Berdasarkan observasi awal penulis, Hotel XYZ dalam pengelolaan operasional hotelnya memiliki kekurangan dalam pengendalian internal persediaan guest supplies-nya karena tidak ada sistem pengendalian internal dan pelaporan atas persediaan yang memadai. Hal ini dapat memicu fraud ataupun kesalahan yang tidak disengaja. Beberapa contoh yang sudah pernah terjadi adalah seperti berikut:

1. Persediaan slipper yang habis dan tidak ada stok yang memadai sehingga membuat beberapa tamu tidak mendapatkan slipper, sedangkan slipper di hotel merupakan hal yang paling mendasar dalam kebutuhan tamu hotel. Hal ini dapat memengaruhi experience review yang buruk dan memengaruhi citra hotel,

2. Pembelian barang yang mendadak dan dibutuhkan waktu yang sesegera mungkin agar stok segera terisi kembali. Hal ini memengaruhi budget yang telah disusun sedemikian rupa sehingga mengganggu pos - pos biaya yang lain.

Dari uraian tersebut, maka perlu adanya perancangan terhadap sistem pengendalian internal persediaan guest supplies yang ada pada housekeeping department di PT XYZ dengan menggunakan COSO 2013 framework sebagai acuan pada penelitian ini. Oleh sebab itu, muncul rumusan masalah tentang bagaimana perancangan sistem pengendalian internal atas persediaan guest supplies pada Housekeeping Department yang memadai bagi Hotel XYZ dengan menggunakan standar framework COSO (Committee of Sponsoring Organization of The Treadway Commission)?

\section{Kajian Pustaka dan Pengembangan Hipotesis \\ Pengendalian Internal}

Menurut COSO 2013 (Committee of Sponsoring Organization of The Treadway Commission) sistem pengendalian internal merupakan suatu proses yang melibatkan dewan komisaris, manajemen, dan personil lain, yang dirancang untuk memberikan keyakinan memadai tentang pencapaian tiga tujuan berikut ini, yaitu:

- Efektivitas dan efisiensi operasi,

- Keandalan pelaporan keuangan,

- Kepatuhan terhadap hukum dan peraturan yang berlaku.

Kerangka kerja pengendalian intern yang diterbitkan oleh COSO dikenal luas dengan sebutan COSO Internal Control Integrated Framework. Lima Komponen COSO 2013 dalam Diana dan Setiawati (2011:83-92) adalah sebagai berikut:

\section{Lingkungan Pengendalian}

Lingkungan pengendalian suatu perusahaan mencakup seluruh sikap manajemen dan karyawan mengenai pentingnya pengendalian. Lingkungan pengendalian sebagai komponen pengendalian yang pertama, meliputi faktor-faktor sebagai berikut:
a. Filosofi Manajemen dan Gaya Operasi
b. Komitmen terhadap Integritas dan Nilai- Nilai Etika
c. Komitmen Terhadap Kompetensi
d. Komite Audit dan Dewan Direksi
e. Struktur Organisasi 
f. Penetapan Otoritas dan Tanggung Jawab

g. Kebijakan dan Praktik Sumber Daya Manusia

2. Aktivitas Pengendalian

Aktivitas pengendalian yang terkait dengan pelaporan keuangan antara lain meliputi:

a. Desain Dokumen yang Baik dan Bernomor Urut Cetak

b. Pemisahan Tugas

c. Otorisasi yang Memadai atas setiap Transaksi Bisnis

d. Mengamankan Harta dan Catatan Perusahaan

e. Menciptakan adanya Pengecekan Independen atas Pekerjaan Karyawan lain

3. Penaksiran Risiko

Organisasi harus menyadari dan waspada terhadap berbagai resiko yang dihadapinya. Organisasi harus pula menetapkan mekanisme untuk mengidentifikasi, menganalisis dan mengelola resiko-resiko terkait.

4. Informasi dan Komunikasi

Informasi harus diidentifikasi, diproses dan dikomunikasikan ke personil yang tepat sehingga setiap orang dalam perusahaan dapat melaksanakan tanggung jawab mereka dengan baik.

5. Pengawasan Kinerja

Kegiatan dalam pegawasan kinerja diantaranya, supervisi yang efektif, akuntansi pertanggungjawaban dan pengauditan internal.

\section{Tujuan Pengendalian Internal}

Menurut Krismiaji (2015: 213) tujuan dilakukannya pengendalian adalah untuk mencegah timbulnya kerugian bagi sebuah organisasi, yang timbul antara lain karena sebab-sebab sebagai berikut:

1. Penggunaan sumber daya yang tidak efisien dan boros,

2. Keputusan manajemen yang tidak baik,
3. Kesalahan yang tidak disengaja dalam pencatatan dan pemrosesan data,

4. Kehilangan atau kerusakan catatan secara tidak sengaja,

5. Kehilangan aktiva karena kecerobohan karyawan,

6. Perubahan secara tidak sah terhadap SIA atau komponen-komponennya.

Menurut Warren, et al (2014: 343) dua tujuan utama dalam pengendalian atas persediaan adalah melindungi persediaaan dari kerusakan atau pencurian serta melaporkan dengan benar dalam laporan keuangan.

\section{Housekeeping Department}

Menurut Hartoni (2015: 14)

Housekeeping department, bagi sebagian besar hotel, merupakan sumber pendapatan yang paling besar, karena tamu yang menginap tentu mengeluarkan uang yang banyak untuk sewa bila dibandingkan dengan uang yang harus dibayarkannya untuk makan dan minum serta pengeluaran yang lain.

Housekeeping Department memiliki bagian - bagian yang dibagi menjadi:

a. Room section: Tugas pokok dari bagian ini adalah menjaga kebersihan, kerapian, keindahan, kenyamanan dan kelengkapan kamar tamu.

b. Public area section: Tugas pokok dari seksi ini adalah menjaga kebersihan, kerapian, keindahan, kenyamanan seluruh area hotel, baik yang ada di luar maupun di dalam hotel kecuali kamar tamu.

c. Linen section: Tugas pokok dari seksi ini adalah menangani keluar masuknya linen yang ada di hotel.

Laundry section: Bagian yang bertanggung jawab tentang semua cucian yang dikirim ke laundry section.

\section{Persediaan Guest Supplies}

Pada industri perhotelan persediaan dibagi berdasarkan fungsinya, menurut 
Larasati (2017) untuk persediaan di dalam perhotelan dibagi menjadi empat tipe, yaitu:

1. Groceries adalah barang persediaan yang berupa bahan baku untuk mengolah masakan seperti sayur, buah, atau bumbu masak.

2. Guest supplies adalah barang persediaan yang bisa dipakai dan digunakan untuk tamu seperti: Straw (sedotan), toothpick (tusuk gigi), creamer sachet, tea sachet, coffee sachet, sugar sachet, slipper (sandal hotel), soap (sabun mandi), shampoo, toothpaste (pasta gigi), shower cap (penutup rambut ketika mandi).

3. Stationary adalah barang persediaan yang berupa alat tulis seperti pensil, pulpen, dan berbagai macam form (captain order, bill restaurant, bill laundry), book 1/4 HVS (kertas mirip note book).

4. Linen adalah barang persediaan berupa kain. Untuk linen sendiri dibagi menjadi 2 yakni milik Housekeeping dan milik Food \& Beverage $(F \& B)$, yaitu:

a. Linen yang digunakan dan disimpan gudang Housekeeping adalah Bed sheet, Bed runner, Bed skirt, Bed cover, Duvet cover \& insert, Bad pad, Pillow case, Blanket, Towel, Bath Mat.

b. Linen yang digunakan dan disimpan di gudang $F \& B$ adalah Table Cloth, Napkin, Skirt, Place Mat, Seat Cover.

Berikut merupakan kerangka berfikir yang penulis gambarkan untuk penelitian studi kasus ini:



Sumber: Data diolah

Gambar 1 Kerangka Berfikir

\section{METODE PENELITIAN}


Jenis penelitian yang digunakan dalam penelitian ini adalah studi kasus. Menurut Pratowo (2014:127) jenis penelitian studi kasus adalah penelitian yang dilakukan secara intensif dan mendetail terhadap suatu kasus. Penelitian ini dilakukan selama Januari - Oktober 2020. Tempat

\section{HASIL DAN PEMBAHASAN}

\section{Alur Pengelolaan Persediaan Barang Guest Supplies Hotel XYZ}

Berikut merupakan alur pengelolaan persediaan barang guest supplies pada Hotel XYZ yang terdiri dari pembelian penelitian dilakukan di Hotel XYZ yang berlokasi di Jl. Sultan Hasanudin, Blok M, Jakarta Selatan. Teknik penelitian dengan wawancara dan dokumentasi. Metode yang digunakan dalam penelitian ini adalah deskriptif kualitatif.

barang serta penyimpanan dan eluar/masuk barang:

a. Pembelian Barang

Pembelian persediaan guest supplies di Hotel XYZ dapat dijabarkan sebagai berikut:

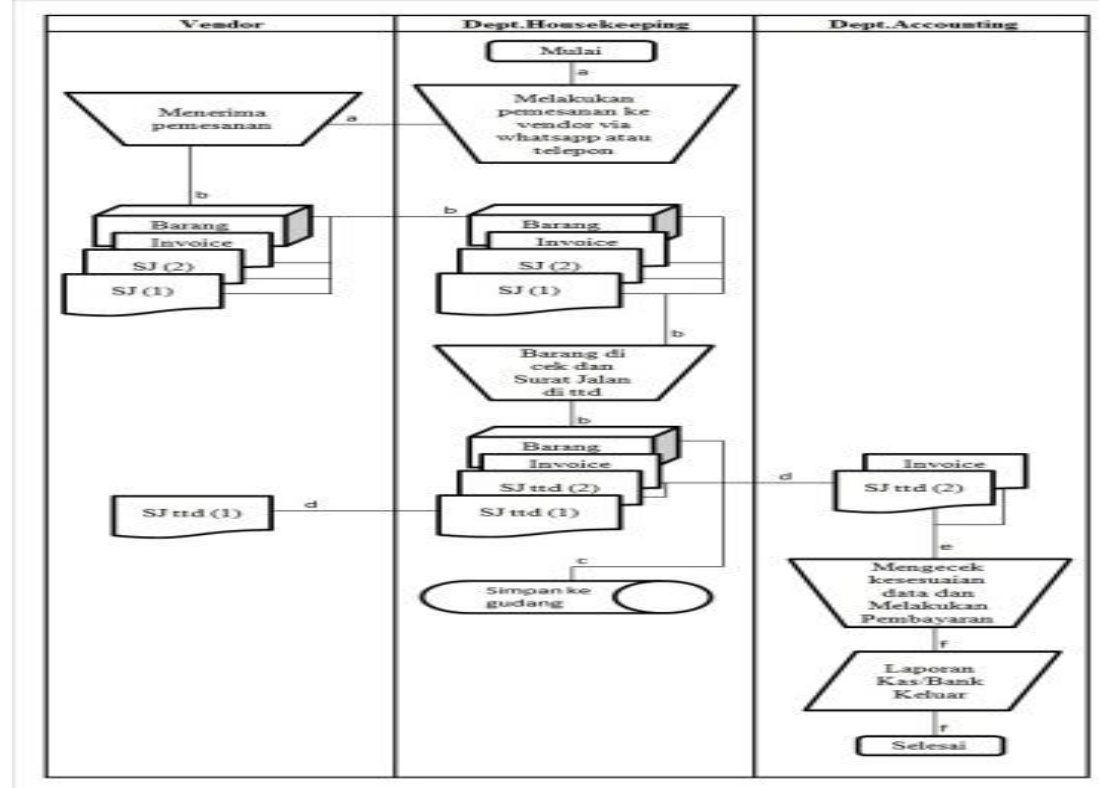

Sumber: Data diolah.

Gambar 2 Flowchart Pembelian Persediaan Guest Supplies Hotel XYZ

Berdasarkan Gambar 4.5.1 maka dapat diperoleh keterangan:
a. Department
Housekeeping
menghubungi vendor melalui telepon maupun whatsapp untuk memesan barang.
b. Vendor mengirimkan barang beserta surat jalan dan invoice kemudian diterima langsung oleh bagian Housekeeping.

c. Jika pembelian dalam jumlah banyak, maka akan disimpan di dalam gudang, namun jika ukuran dus guest supplies tersebut masih cukup disimpan di ruang Housekeeping, maka akan disimpan di Housekeeping.

d. Invoice dari vendor/supplier akan diberikan kepada bagian accounting melalui bagian housekeeping. 
e. Accounting akan mengecek invoice tersebut dengan surat jalan, jika sesuai, maka accounting akan merencanakan pembayaran atas invoice tersebut. f. Accounting akan membayar dengan dua cara, yaitu membayar melalui petty cash, atau membuat cek yang ditandatangani oleh owner dan dikeluarkan melalui saldo bank hotel XYZ.

b. Alur Barang Masuk dan Barang Keluar

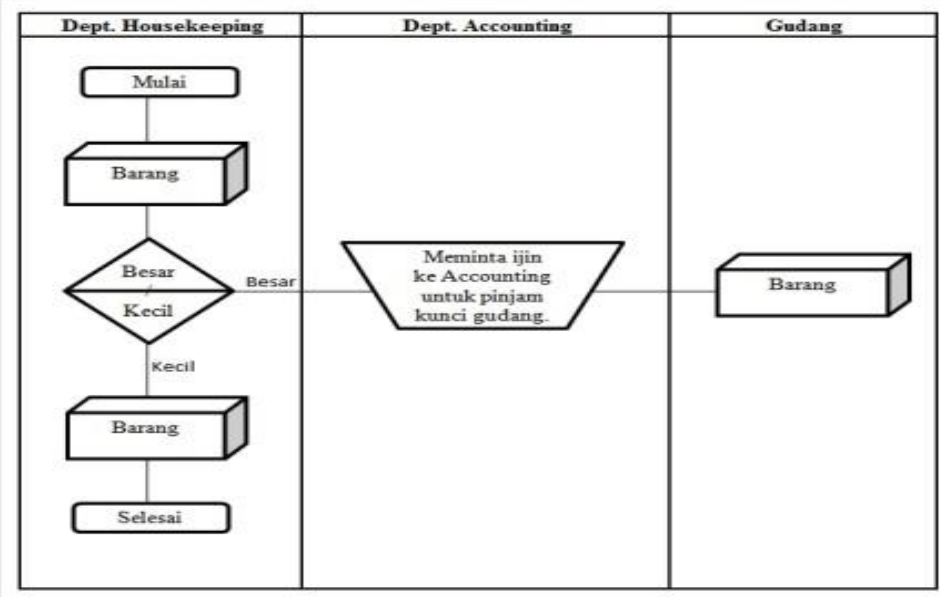

Sumber: Data diolah

Gambar 3 Flowchart Barang Masuk Persediaan Guest Supplies Hotel XYZ

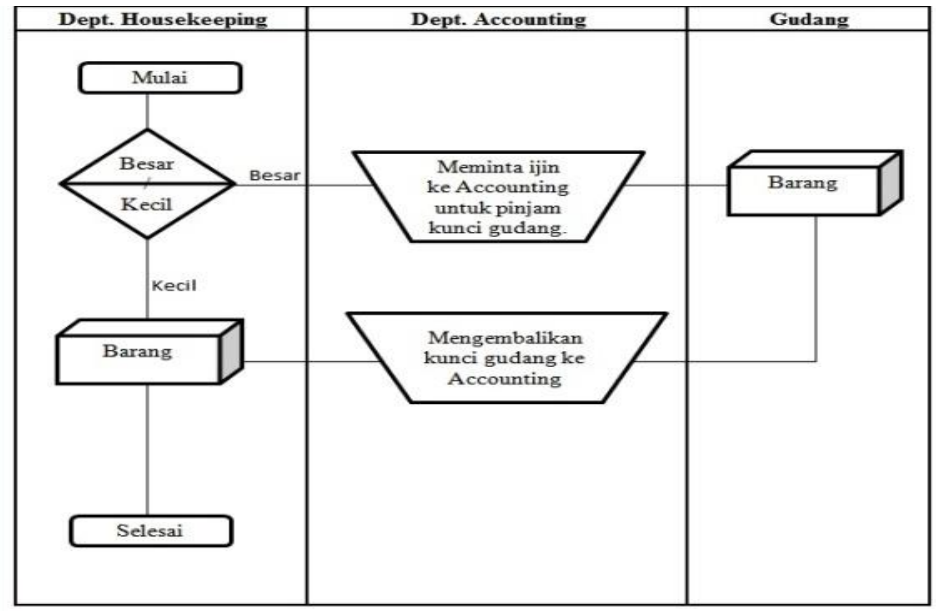

Sumber: Data diolah

Gambar 4 Flowchart Barang Keluar Persediaan Guest Supplies Hotel XYZ

Berdasarkan Gambar 3 dan 4 maka dapat diperoleh keterangan seperti berikut:

1. Barang yang telah dipesan oleh department housekeeping, maka akan disimpan gudang penyimpanan.
2. Untuk dus berukuran besar disimpan pada gudang penyimpanan, namun untuk dus ukuran kecil akan langsung disimpan pada ruangan department housekeeping. 
3. Untuk penyimpanan di gudang maupun di department housekeeping tidak ada kartu stok ataupun laporan persediaan atas barang tersebut.

4. Kunci gudang penyimpanan disimpan oleh bagian accounting namun semua karyawan yang berkepentingan maupun tidak berkepentingan bebas keluar masuk gudang penyimpanan setelah sebelumnya meminjam kunci gudang ke bagian accounting.

5. Barang guest supplies yang sudah disimpan di ruangan department housekeeping dan gudang tidak memiliki pencatatan untuk keluar masuk barang.

Kebutuhan atas pemakaian barang di department housekeeping berdasarkan oleh jumlah tamu yang datang dan kamar yang terjual pada periode waktu tersebut.

\section{Kelemahan atas Prosedur Yang Berjalan di Hotel XYZ}

Berikut adalah beberapa kelemahan - kelemahan yang ada pada prosedur pengelolaan barang guest supplies di Hotel XYZ:

1. Tidak ada laporan pencatatan persediaan dalam bentuk excel maupun manual. Kondisi tersebut dapat menyebabkan tidak dapat ditelusurinya pemakaian persediaan dalam satu periode dan tidak terawasinya pemakaian persediaan yang dapat menyebabkan pemborosan pemakaian barang sehingga sulit untuk dilakukan evaluasi.

2. Tidak ada orang yang bertugas khusus untuk mengelola suatu gudang besar untuk penyimpanan semua persediaan barang habis pakai. Sehingga dapat menyebabkan tidak ada yang dapat diminta pertanggungjawaban atas barang yang habis mendadak, kelebihan pemesanan, rusak, ataupun kadaluarsa.
3. Pegawai bebas keluar-masuk gudang penyimpanan. Kondisi tersebut dapat menyebabkan lemahnya kontrol terhadap persediaan barang, risiko hilang persediaan barang meningkat, kerusakan barang akibat kondisi gudang yang tidak steril, dan lain sebagainya.

4. Gudang penyimpanan hanya untuk barang - barang dengan ukuran dus besar yang belum terbuka. Sedangkan dus berukuran kecil atau dus yang sudah terbuka langsung disimpan pada ruang penyimpanan departemen terkait. Kondisi tersebut dapat menyebabkan risiko barang mudah rusak, mudah tumpah, dan tidak tertatanya tempat persediaan barang yang ada.

5. Tidak ada pencatatan, pengecekan dan pengawasan dari manajemen. Kondisi tersebut dapat menyebabkan beberapa risiko seperti tidak berjalannya SOP yang seharusnya berjalan, pemborosan pemakaian maupun pemborosan pemesanan barang, penyalahgunaan wewenang, hingga risiko barang hilang maupun rusak.

6. Tidak ada otorisasi lebih lanjut dari manajemen atas dokumen dokumen pembelian dan penyimpanan barang guest supplies. Hal tersebut menyebabkan dapat terjadinya penyimpangan dalam pengelolaan kas/bank hotel dan pengelolaan persediaan hotel.

7. Pemesanan barang ke supplier dilakukan langsung oleh bagian yang memerlukan bukan dari bagian lain yang khusus mengelola pembelian barang. Kondisi tersebut dapat meningkatkan risiko adanya kecurangan dalam proses pembelian, misalnya seperti mark-up harga dan penurunan atau tidak sesuainya kualitas barang yang dipesan.

8. Tidak ada stock opname atas persediaan di gudang penyimpanan 
maupun per departemen. Kondisi tersebut dapat menyebabkan ketidaksesuaian jumlah persediaan antara persediaan fisik dengan pencatatan akuntansi yang akhirnya laporan keuangan yang disajikan menjadi tidak akurat, sedangkan persediaan akhir periode berjalan merupakan persediaan awal periode berikutnya, maka dari itu penyesuaian persediaan dengan adanya stock opname penting untuk fungsi pembanding dan analisis.

\section{Perancangan Sistem Pengendalian Internal Persediaan Barang Guest Supplies Berdasarkan COSO di Housekeeping Department}

Berdasarkan hasil observasi dan wawancara dari beberapa pihak terkait (dokumen hasil observasi dan wawancara seperti pada lampiran 1), berikut rancangan yang dapat diusulkan untuk 4. untuk diketahui. sistem pengendalian internal persediaan barang guest supplies dengan mempertimbangkan tidak adanya penambahan jumlah karyawan dan rata rata occupancy yang rendah yaitu hanya $36,80 \%$ perbulan:

1. Menunjuk satu orang bagian Housekeeping menjadi bagian yang bertugas khusus untuk melaksanakan pengendalian pemakaian barang guest supplies di Department Housekeeping.

2. Masing - masing department disarankan memiliki kepala bagian atau minimal bagian administrasi yang ditunjuk untuk fungsi otorisasi dan penyampaian laporan per periode.

3. Pencatatan persediaan dilakukan setiap akhir bulan dan ditandatangani masing - masing oleh staf housekeeping yang ditunjuk di poin 1 dan oleh bagian accounting

Tabel 2 Tabel Acuan Perencanaan Sistem Pengendalian Internal 
Tiara Ratna Biandari, Ludwina Harahap/ Perancangan Sistem Pengendalian Internal Persediaan Barang Guest Supplies Pada Department Housekeeping Di Hotel XYZ

\begin{tabular}{|c|c|c|c|c|}
\hline No. & & Unsur Pengendalian COSO & $\begin{array}{c}\text { Kekurangan Pengelolaan Hotel } \\
\text { XYZ }\end{array}$ & Solusi \\
\hline \multirow{2}{*}{\multicolumn{2}{|c|}{1 I }} & \multicolumn{3}{|c|}{ Lingkungan Pengendalian } \\
\hline & & $\begin{array}{l}\text { Filosofi Manajemen dan Gaya } \\
\text { Operasi }\end{array}$ & $\begin{array}{l}\text { Tidak adanya PIC atau orang yang } \\
\text { bertanggung jawab harian terhadap } \\
\text { operasional hotel. }\end{array}$ & $\begin{array}{l}\text { Menunjuk PIC agar jalannya } \\
\text { operasional hotel bisa terkontrol } \\
\text { dengan baik dan laporan } \\
\text { diinformasikan kepada owner } \\
\text { secara rutin. }\end{array}$ \\
\hline & b. & $\begin{array}{l}\text { Komitmen terhadap Integritas } \\
\text { dan Nilai- Nilai Etika }\end{array}$ & $\begin{array}{l}\text { Tidak ada peraturan tertulis yang } \\
\text { mengatur tentang kode etik atau } \\
\text { perilaku. }\end{array}$ & $\begin{array}{l}\text { Membuat suatu peraturan tertulis } \\
\text { yang terdiri dari SOP, kode etik, } \\
\text { dan sanksi. }\end{array}$ \\
\hline & c. & $\begin{array}{l}\text { Komitmen Terhadap } \\
\text { Kompetensi }\end{array}$ & $\begin{array}{l}\text { Tidak ada orang yang bertugas } \\
\text { khusus untuk mengelola suatu gudang } \\
\text { besar untuk penyimpanan semua } \\
\text { persediaan barang guest supplies. }\end{array}$ & $\begin{array}{l}\text { Menunjuk satu orang staf bagian } \\
\text { housekeeping untuk melakukan } \\
\text { pencatatan serta mengelola } \\
\text { penyimpanan persediaan guest } \\
\text { supplies. }\end{array}$ \\
\hline & d. & $\begin{array}{l}\text { Komite Audit dan Dewan } \\
\text { Direksi }\end{array}$ & $\begin{array}{l}\text { Tidak ada pencatatan, pengecekan } \\
\text { dan pengawasan dari manajemen. }\end{array}$ & $\begin{array}{l}\text { Pencatatan dan pelaporan } \\
\text { dilakukan secara rutin dan owner } \\
\text { melakukan kunjungan serta review } \\
\text { secara berkala ke Hotel XYZ agar } \\
\text { ada komunikasi dan pengawasan } \\
\text { secara langsung. }\end{array}$ \\
\hline & e. & Struktur Organisasi & Minim divisi serta tidak ada supervisi. & $\begin{array}{l}\text { Menambah divisi yang diperlukan } \\
\text { seperti bagian gudang maupun } \\
\text { purchasing, serta menambah jumlah } \\
\text { karyawan agar jam kerja lebih } \\
\text { proporsional. }\end{array}$ \\
\hline & f. & $\begin{array}{l}\text { Penetapan Otoritas dan } \\
\text { Tanggung Jawab }\end{array}$ & $\begin{array}{l}\text { Pemesanan barang ke supplier } \\
\text { dilakukan langsung oleh bagian yang } \\
\text { memerlukan bukan dari bagian lain } \\
\text { yang khusus mengelola pembelian } \\
\text { barang. }\end{array}$ & $\begin{array}{l}\text { Memberikan penetapan yang lebih } \\
\text { jelas akan SOP yang berlaku, serta } \\
\text { memberikan penunjukan atas } \\
\text { wewenang agar tidak terjadi } \\
\text { rangkap jabatan yang membuat } \\
\text { bias tanggung jawab. }\end{array}$ \\
\hline & g. & $\begin{array}{l}\text { Kebijakan dan Praktik Sumber } \\
\text { Daya Manusia }\end{array}$ & $\begin{array}{l}\text { Ketiadaan manajer dan kurangnya } \\
\text { ketersediaan sumber daya manusia } \\
\text { pada hotel XYZ serta tidak adanya } \\
\text { pelatihan keahlian untuk pegawai. }\end{array}$ & $\begin{array}{l}\text { Mengadakan pelatihan keahlian, } \\
\text { mengadakan posisi manajer } \\
\text { ataupun supervisor agar ada } \\
\text { kontrol operasional, serta } \\
\text { menambah ketersediaan sdm. }\end{array}$ \\
\hline
\end{tabular}


Tiara Ratna Biandari, Ludwina Harahap/ Perancangan Sistem Pengendalian Internal Persediaan Barang Guest Supplies Pada Department Housekeeping Di Hotel XYZ

\begin{tabular}{|c|c|c|c|c|}
\hline \multirow{2}{*}{$\frac{1}{2}$} & \multicolumn{4}{|c|}{ Aktivitas Pengendalian } \\
\hline & a. & $\begin{array}{l}\text { Desain Dokumen yang Baik } \\
\text { dan Bernomor Urut Cetak }\end{array}$ & $\begin{array}{l}\text { Tidak ada penggunaan dokumen } \\
\text { pada bagian housekeeping. }\end{array}$ & $\begin{array}{l}\text { Mengadakan penggunaan dokumen } \\
\text { bernomor urut cetak yang } \\
\text { berhubungan dengan operasional } \\
\text { housekeeping terlebih yang } \\
\text { berhubungan dengan jalannya } \\
\text { pengendalian internal guest } \\
\text { supplies. }\end{array}$ \\
\hline & b. & Pemisahan Tugas & $\begin{array}{l}\text { Pemesanan barang ke supplier } \\
\text { dilakukan langsung oleh bagian yang } \\
\text { memerhukan bukan dari bagian lain } \\
\text { yang khusus mengelola pembelian } \\
\text { barang. }\end{array}$ & $\begin{array}{l}\text { Memberikan penetapan yang lebih } \\
\text { jelas akan SOP yang berlaku, serta } \\
\text { memberikan penunjukan atas } \\
\text { wewvenang agar tidak terjadi } \\
\text { rangkap jabatan yang membuat } \\
\text { bias tanggung jawab. }\end{array}$ \\
\hline & c. & $\begin{array}{l}\text { Otorisasi yang Memadai atas } \\
\text { setiap Transaksi Bisnis }\end{array}$ & $\begin{array}{l}\text { Tidak ada otorisasi lebih lanjut dari } \\
\text { Management atas dokumen - } \\
\text { dokumen pembelian dan } \\
\text { penyimpanan barang guest supplies. }\end{array}$ & $\begin{array}{l}\text { Owner wajib melakukan analisis } \\
\text { dan neview berkala atas } \\
\text { pengendalian internal dan } \\
\text { pembukuan hotel apakah sudah } \\
\text { sesuai dengan SOP yang berlaku. }\end{array}$ \\
\hline & d. & $\begin{array}{l}\text { Mengamankan Harta dan } \\
\text { Catatan Perusahaan }\end{array}$ & $\begin{array}{l}\text { Pegawai bebas kehuar-masuk gudang } \\
\text { penyimpanan. (Tidak ada bagian } \\
\text { Gudang) }\end{array}$ & $\begin{array}{l}\text { Hanya staf housekeeping yang } \\
\text { telah ditunjuk untuk mengelola } \\
\text { persediaan barang guest supplies } \\
\text { saja yang boleh kehuar-masuk } \\
\text { gudang penyimpanan. }\end{array}$ \\
\hline & & & $\begin{array}{l}\text { Gudang penyimpanan hanya untuk } \\
\text { barang - barang dengan ukuran dus } \\
\text { besar yang belum terbuka. } \\
\text { Sedangkan dus berukuran kecil atau } \\
\text { dus yang sudah terbuka langsung } \\
\text { disimpan pada ruang penyimpanan } \\
\text { departemen terkait. }\end{array}$ & $\begin{array}{l}\text { Penyimpanan guest supplies } \\
\text { seluruhnya disimpan di dalam } \\
\text { gudang dan tidak ada yang } \\
\text { disimpan di dalam ruangan } \\
\text { housekeeping agar mengurangi } \\
\text { kekeliruan pencatatan fisik dan } \\
\text { frad yang mungkin terjadi seperti } \\
\text { contohnya tidak terdeteksinya } \\
\text { barang yang digunakan karena } \\
\text { berada di ruangan terbuka atau } \\
\text { kecerobohan dalam bekerja } \\
\text { misalnya tumpah, dil. }\end{array}$ \\
\hline & e. & $\begin{array}{l}\text { Menciptakan adanya } \\
\text { Pengecekan Independen atas } \\
\text { Pekerjaan Karyawan lain }\end{array}$ & $\begin{array}{l}\text { Tidak ada stock opmame atas } \\
\text { persediaan di gudang penyimpanan } \\
\text { maupun per departemen. }\end{array}$ & $\begin{array}{l}\text { Staf housekeeping yang telah } \\
\text { ditunjuk untuk mengelola } \\
\text { persediaan diwajibkan melakukan } \\
\text { pencatatan fisik berkala yang } \\
\text { diinput ke dalam inventory } \\
\text { report. }\end{array}$ \\
\hline \multicolumn{3}{|c|}{ Penaksiran Resiko } & $\begin{array}{l}\text { Pegawai bebas kehuar-masuk gudang } \\
\text { penyimpanan. (Tidak ada bagian } \\
\text { Gudang) }\end{array}$ & $\begin{array}{l}\text { Hanya staf housekeeping yang } \\
\text { telah ditunjuk untuk mengelola } \\
\text { persediaan barang guest supplies } \\
\text { saja yang boleh keluar-masuk } \\
\text { gudang penyimpanan. }\end{array}$ \\
\hline 47 & \multicolumn{2}{|r|}{ Informasi dan Komunikasi } & $\begin{array}{l}\text { Komunikasi secara vertikal kurang } \\
\text { efektif karena garis komando yang } \\
\text { tidak jelas } \\
\text { Informasi yang diberikan tidak dapat } \\
\text { dipertanggungjawablcan karena tidak } \\
\text { ada laporan atas persediaan barang } \\
\text { guest supplies secara tulisan }\end{array}$ & $\begin{array}{l}\text { Pertegas struktur organisasi dengan } \\
\text { adanya supervisi yang jelas } \\
\text { Buat laporan atas persediaan } \\
\text { barang guest supplies yang } \\
\text { ditandatangani oleh divisi terkait. }\end{array}$ \\
\hline \multirow[t]{4}{*}{5} & \multicolumn{4}{|c|}{ Pengawasan Kinerja } \\
\hline & a. & Supervisi yang efektif & $\begin{array}{l}\text { Tidak ada supervisi maupun PIC yang } \\
\text { bisa diandalkan untuk pengawasan } \\
\text { kinerja, serta tidak ada pengawasan } \\
\text { langsung dari owner. }\end{array}$ & $\begin{array}{l}\text { Menunjuk PIC agar jalannya } \\
\text { operasional hotel bisa terkontrol } \\
\text { dengan baik serta adanya } \\
\text { pengawasan berkala dari owner. }\end{array}$ \\
\hline & b. & Akuntansi pertanggungjawaban & $\begin{array}{l}\text { Tidak ada laporan pencatatan } \\
\text { persediaan dalam bentuk excel } \\
\text { maupun mamual. }\end{array}$ & $\begin{array}{l}\text { Staf housekeeping dan } \\
\text { accounting diwajibkan untuk } \\
\text { melakukan pencatatan persediaan } \\
\text { dengan dokumen manual maupun } \\
\text { penginputan data yang } \\
\text { terkomputerisasi. }\end{array}$ \\
\hline & c. & Pengauditan internal & $\begin{array}{l}\text { Tidak ada otorisasi lebih lanjut dari } \\
\text { manajemen atas dokumen - dokumen } \\
\text { pembelian dan penyimpanan barang } \\
\text { guest supplies. }\end{array}$ & $\begin{array}{l}\text { Owner wajib melakukan analisis } \\
\text { dan neview berkala atas } \\
\text { pengendalian internal dan } \\
\text { pembukuan hotel apakah sudah } \\
\text { sesuai dengan SOP yang berlaku. }\end{array}$ \\
\hline
\end{tabular}

Sumber: Data diolah. 
Tabel 2 memberikan gambaran secara umum tentang permasalahan dan solusi yang penulis berikan untuk studi kasus pada Hotel XYZ.
Berikut merupakan flowchart atas perencanaan pengendalian internal guest supplies pada Hotel XYZ:

- Perencanaan pengendalian internal atas pembelian barang guest supplies:

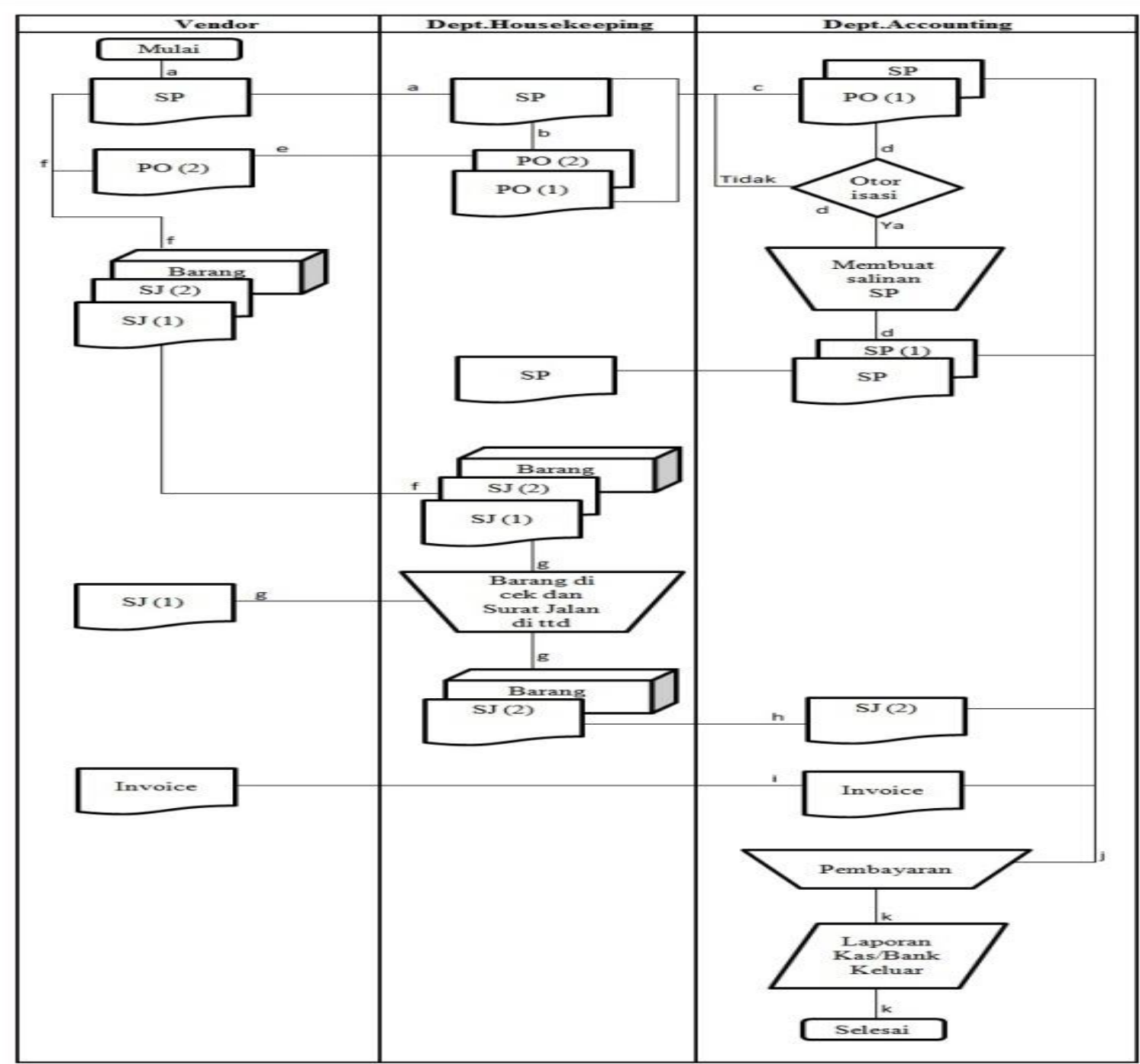

Sumber: Data diolah

Gambar 5 Perancangan Flowchart Pembelian Persediaan Guest Supplies

Berdasarkan Gambar 5 maka dapat diperoleh keterangan seperti berikut:

a. Vendor akan mengirimkan surat penawaran kepada bagian admin housekeeping.

b. Housekeeping akan membuat purchase order dua rangkap berdasarkan surat penawaran yang dikirimkan oleh vendor. Dokumen perancangan purchase order yang akan digunakan seperti yang terlihat pada Gambar 4.8.9.

c. Housekeeping akan mengirimkan surat penawaran dan purchase order dua rangkap kepada bagian 
accounting untuk otorisasi persetujuan permintaan pembelian.

d. Jika accounting menyetujui permintaan pembelian tersebut, maka accounting akan membuat salinan surat penawaran dan purchase order asli akan disimpan di accounting. Sedangkan, purchase order rangkap kedua dan surat penawaran asli akan dikembalikan ke housekeeping.

e. Housekeeping akan mengirimkan purchase order rangkap kedua akan dikirim ke vendor melalui email.

f. Berdasarkan purchase order yang dikirimkan oleh housekeeping dan surat penawaran, maka vendor akan mengirimkan barang beserta surat jalan. Kedua hal itu akan diterima oleh bagian housekeeping.

g. Housekeeping akan melakukan pengecekan kesesuaian barang dengan surat jalan, jika sesuai maka housekeeping akan menandatangan surat jalan yang sudah terlebih dahulu ditandatangani oleh vendor. Surat jalan asli untuk vendor dan surat jalan copy diterima housekeeping.

h. Setelah itu, housekeeping akan menyimpan barang di gudang dan surat jalan rangkap kedua diberikan ke accounting.

i. Invoice dikirimkan oleh vendor dan diterima oleh accounting .

j. Accounting akan melakukan pembayaran setelah dilakukan pecengekan dan kesesuaian data antara invoice, surat penawaran, copy surat jalan dan asli purchase order.

k. Setelah dilakukan pembayaran oleh accounting, maka akan dimasukan ke dalam laporan kas/bank dan kemudian akan dilaporkan kepada owner.

Perancangan pengendalian internal atas pengelolaan barang guest supplies housekeeping department:

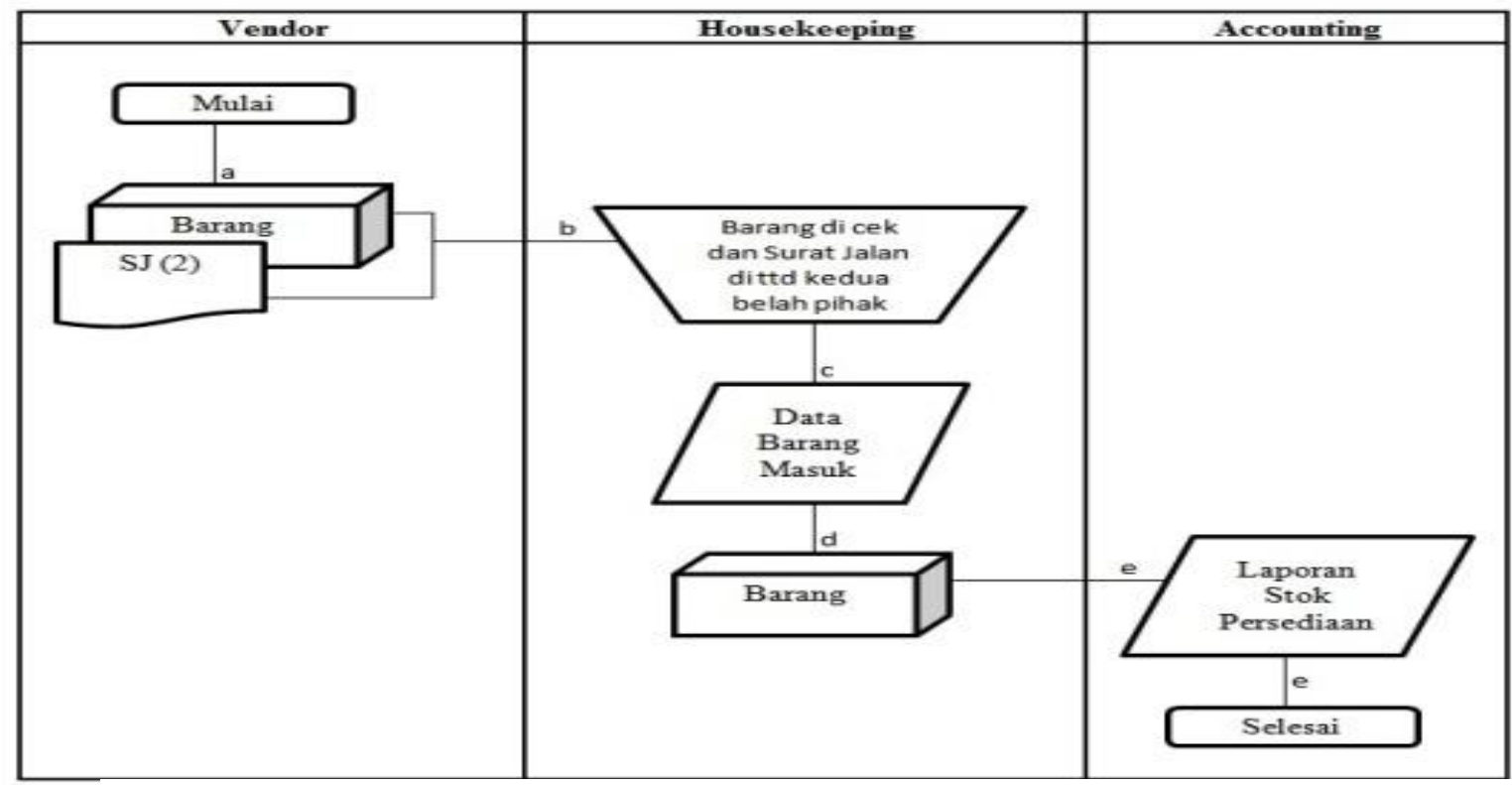

Sumber: Data diolah.

Gambar 6 Perancangan Flowchart Barang Masuk Persediaan Guest Supplies 


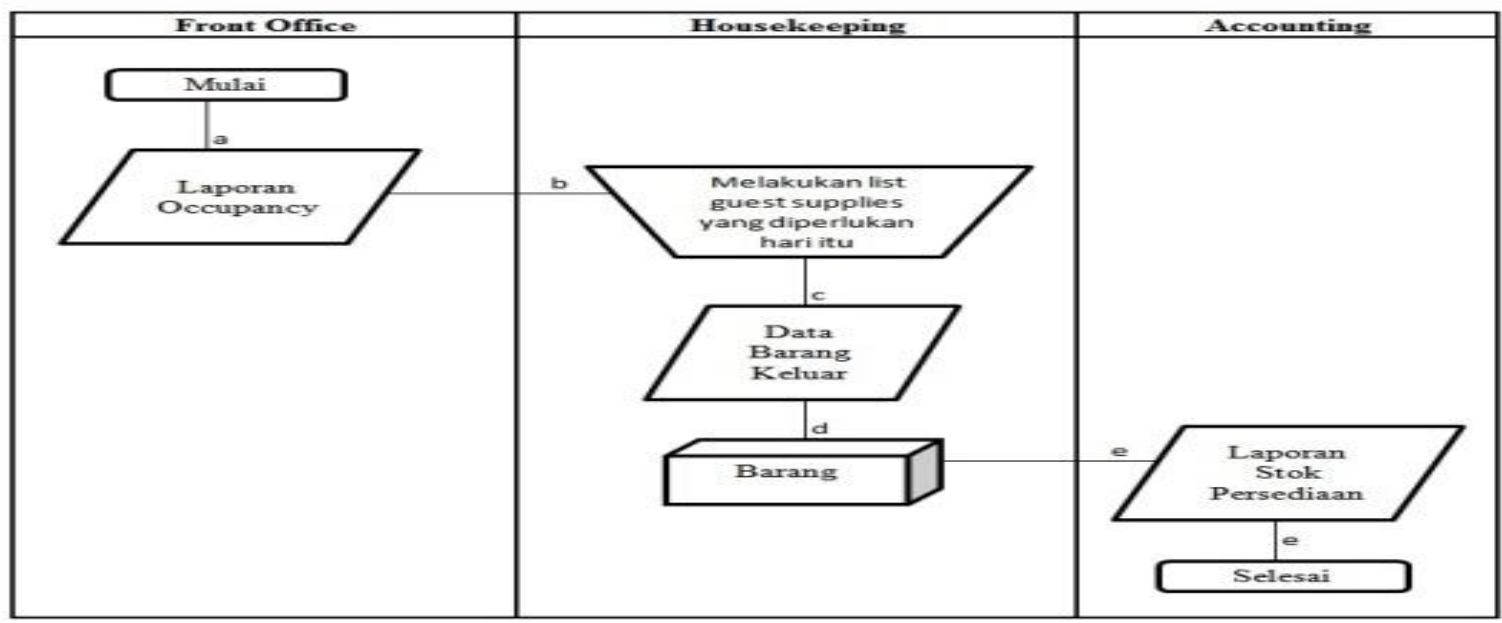

Sumber: Data diolah.

Gambar 7 Perancangan Flowchart Barang Keluar Persediaan Guest Supplies

Berdasarkan Gambar 6 dan 7 maka dapat diperoleh keterangan seperti berikut:

a. Bagian housekeeping yang ditunjuk sebagai admin untuk mengelola persediaan barang guest supplies harus melakukan pemeriksaan barang dan pencatatan barang masuk maupun keluar setiap harinya.

b. Admin bagian housekeeping akan membuat laporan atas barang masuk maupun keluar dengan ditandatangani oleh kedua belah pihak yaitu admin housekeeping dan housekeeping operasional.

c. Setiap akhir bulan admin housekeeping akan membuat stock opname yang menjadi dasar perhitungan persediaan di awal bulan dan melaporkannya kepada bagian accounting.

Dalam melakukan tugas sebagai housekeeping, department tersebut juga perlu menambah dokumen yang dipergunakan dalam keseharian menjalankan tugas, terlebih dokumen ini berhubungan langsung dengan persediaan guest supplies. Dokumen yang harus diadakan yaitu adalah:

a. Room Attendant Control Sheet, yaitu formulir yang digunakan oleh Roomboy saat membersihkan kamar untuk mencatat pemakaian guest amenities dan guest supplies. Berikut saran perancangan dokumen:



Coi






\section{Gambar 8 Perancangan Dokumen Room Attendant Control Sheet}

Dokumen 4.8.4 diisi dan ditandatangani oleh staf housekeeping yang bertugas ke area kamar atau disebut roomboy dan diketahui oleh staf housekeeping yang bertugas dalam pencatatan persediaan. b. Inventory Report, yaitu formulir yang digunakan untuk mencatat dan mengontrol perlengkapan tamu maupun bagian housekeeping, yang meliputi linen, guest supplies, cleaning supplies, uniform. Berikut saran perancangan dokumen:

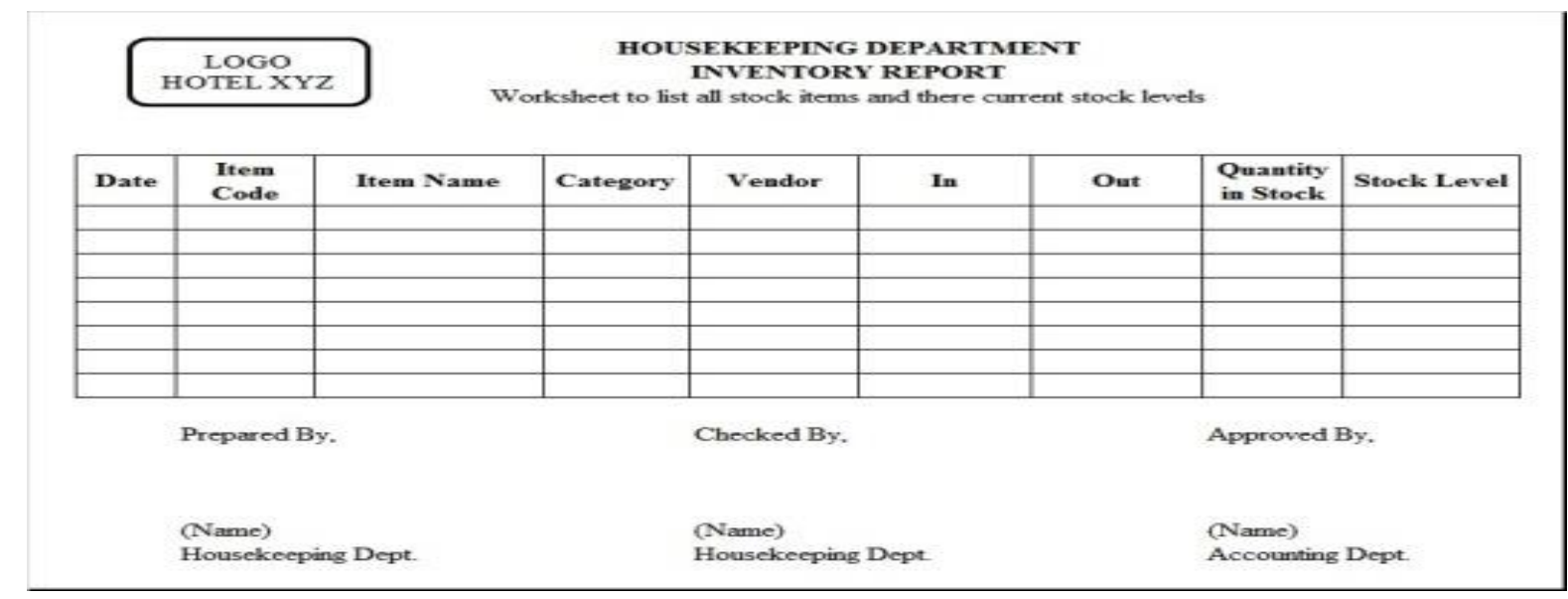

Gambar 9 Perancangan Dokumen Inventory Report

Dokumen tersebut diisi dan ditandatangani oleh staf housekeeping yang bertugas dalam pencatatan persediaan dan diketahui oleh bagian accounting agar dapat digunakan untuk penyesuaian di laporan accounting. c. Lost and Damages Report, yaitu formulir untuk mencatat dan melaporkan barang atau perlengkapan kamar yang hilang, dibawa tamu maupun rusak. Berikut saran perancangan dokumen:




Gambar 10 Perancangan Dokumen Lost and Damages Report

Dokumen tersebut diisi dan ditandatangani pada bagian reported by oleh staf housekeeping yang bertugas ke area kamar atau disebut roomboy. d. Guest Supplies Report, yaitu formulir yang digunakan untuk melaporkan jumlah pemakaian obat/ alat pembersih dan perlengkapan tamu yang dipergunakan di kamar. Berikut saran perancangan dokumen:

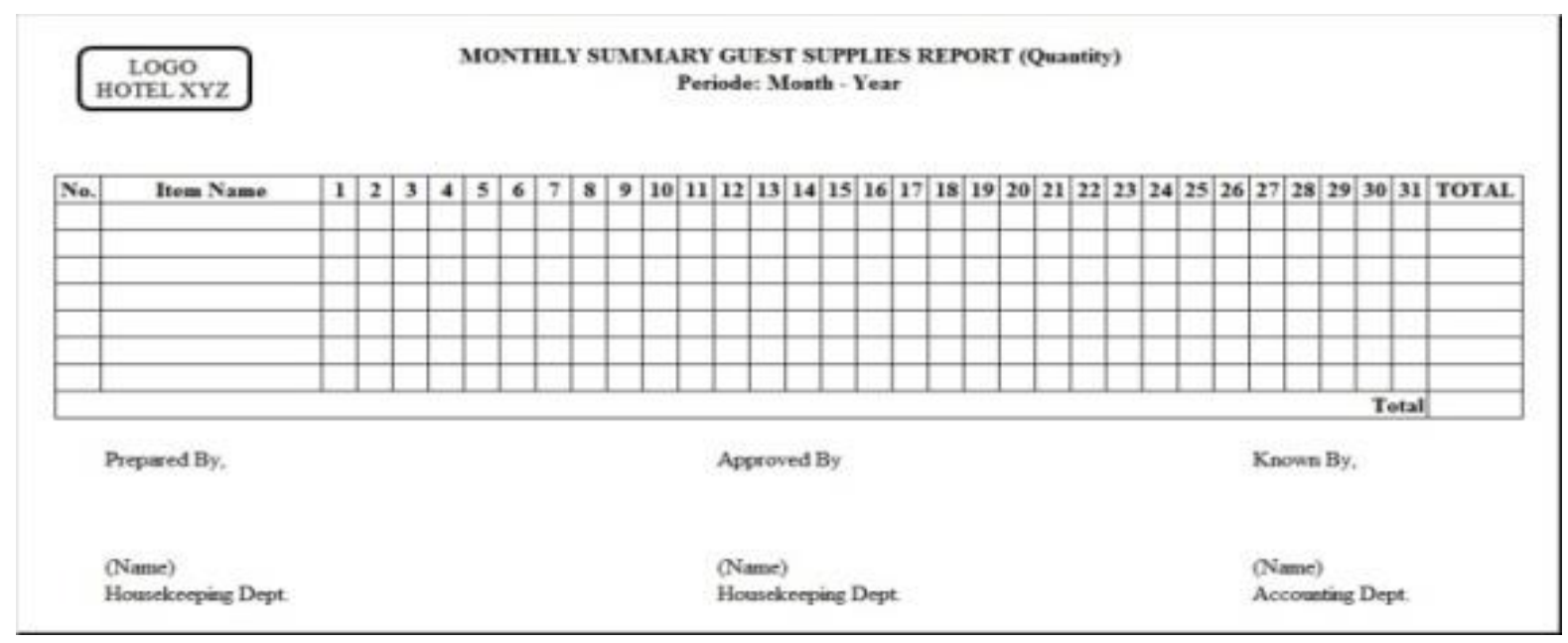

Gambar 11 Perancangan Dokumen Guest Supplies Report

Dokumen tersebut diisi dan ditandatangani oleh staf housekeeping yang bertugas dalam pencatatan persediaan dan diketahui oleh bagian accounting. e. Log Book, yaitu buku catatan mengenai laporan dari shift satu ke shift berikutnya. Berguna untuk menyampaikan masalah maupun pekerjaan yang telah diselesaikan. Berikut saran perancangan dokumen:

\begin{tabular}{|c|c|c|c|c|c|}
\hline \multicolumn{2}{|c|}{$\begin{array}{l}\text { LOGO HOTEL } \\
\text { XYZ } \\
\end{array}$} & & \multicolumn{3}{|c|}{$\begin{array}{l}\text { HOUSEKEEPING DEPARTMENT } \\
\text { Log Book }\end{array}$} \\
\hline Date & Shift & No. & Description Job Pending & Remark & Sign With Name \\
\hline & & & & & \\
\hline & & & & & \\
\hline & & & & & \\
\hline & & & & & \\
\hline & & & & & \\
\hline & & & & & \\
\hline & & & & & \\
\hline & & & & & \\
\hline & & & & & \\
\hline
\end{tabular}

Gambar 12 Perancangan Dokumen Log Book Housekeeping 
f. Purchase Order, yaitu dokumen untuk melakukan pemesanan barang kepada vendor. Berikut saran perancangan dokumen:

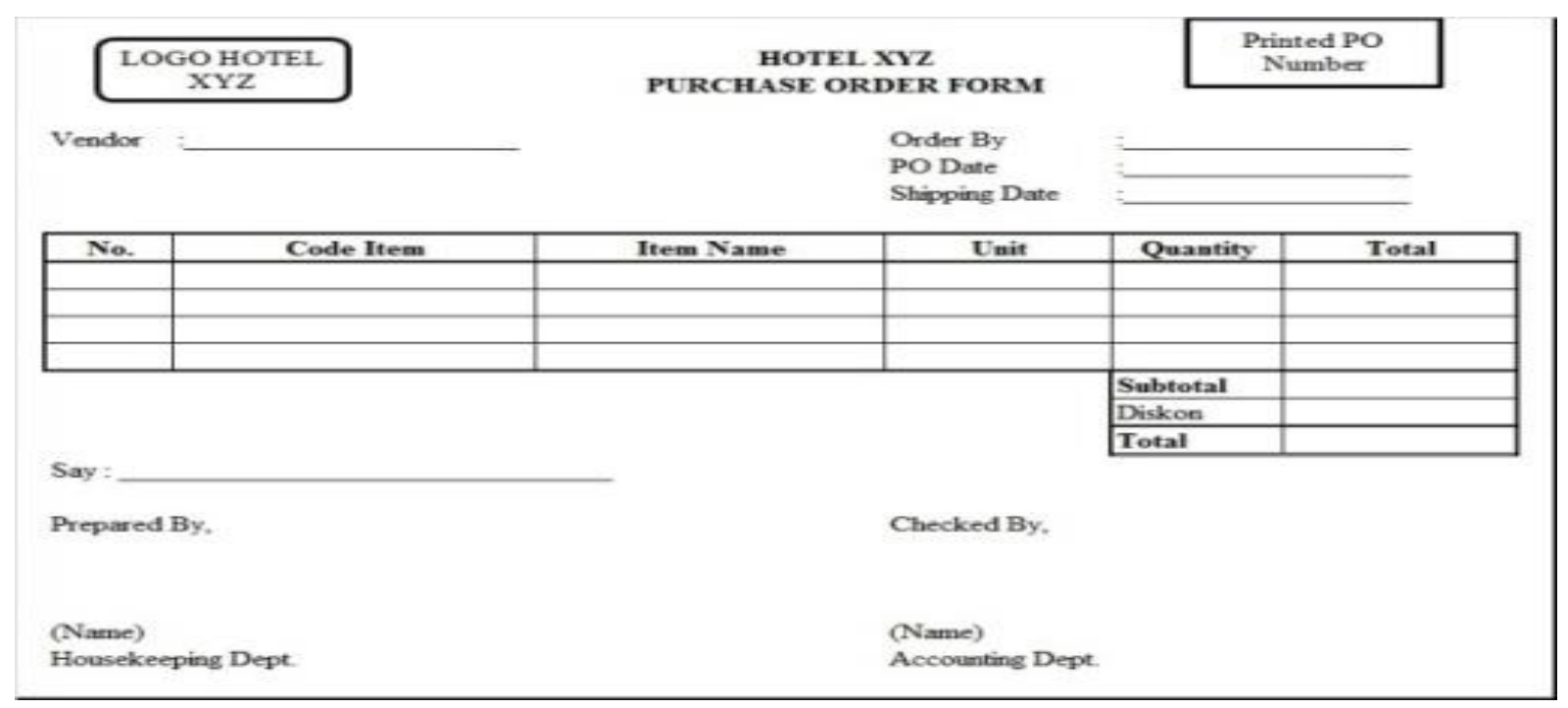

Gambar 13 Perancangan Dokumen Purchase Order

Dokumen tersebut diisi dan ditandatangani oleh staf housekeeping yang bertugas dalam pemesanan persediaan dan disetujui oleh bagian accounting.

\section{PENILAIAN KELAYAKAN ATAS PERANCANGAN SPI PERSEDIAAN GUEST SUPPLIES}

Departemen housekeeping memiliki waktu masing - masing 20 menit untuk mengerjakan satu buah kamar dengan jumlah maksimal masing - masing staf yaitu 18 kamar. Sehingga, dalam sehari masing - masing staf housekeeping operasional menghabiskan waktu 360 menit yang bila dikonversikan ke dalam hitungan jam yaitu 6 jam kerja dalam sehari. Staf housekeeping masing - masing memiliki kelebihan waktu 2 jam yang dapat dimanfaatkan untuk penyesuaian fungsi karyawan yang dirancang pada sistem pengendalian internal persediaan guest supplies.

Berikut merupakan perhitungan atas penilaian kelayakan dari penerapan perancangan sistem pengendalian internal persediaan guest supplies pada Hotel XYZ:

1. Metode periode pengembalian (payback period), yaitu metode ini menilai proyek investasi dengan dasar lamanya investasi tersebut dapat tertutup dengan aliran kas masuk.

Nilai perencanaan pengadaan SPI persediaan guest supplies adalah sebesar Rp 11.500.000. Estimasi umur ekonomis selama satu tahun, dan berikut rincian cash in flow selama tiga tahun kedepan:

Tahun 2021 Rp 248.587.210

Tahun 2022 Rp 261.016.570

Tahun 2023 Rp 274.067.399

Maka perhitungan payback period untuk pengadaan SPI persediaan guest supplies ini adalah:

\begin{tabular}{lr} 
Nilai Investasi & $11,500,000$ \\
Arus kas masuk 2021 & $248,587,210$ \\
\hline Sisa Investasi & $(237,087,210)$
\end{tabular}


Karena sisa investasi pada selisih arus kas masuk pertama sudah negatif, maka dapat langsung dihitung ke bilangan bulan dan hari.

$\begin{aligned} & 11,500,000 \\ & 248,587,210\end{aligned}$ Hari.
Maka,
pengadaan $=0,55 \times 30$ Hari $=16,65$
internal persediaan guest supplies ini
dapat diterima atau layak untuk
dijalankan.

2. Metode pengembalian investasi (return of investment), yaitu metode pengembalian investasi digunakan untuk mengukur persentase manfaat yang dihasilkan oleh proyek dibandingkan dengan biaya yang dikeluarkannya. Return on investment (ROI) dari suatu proyek investasi dapat dihitung dengan rumus :

ROI $=($ Total Manfaat - Total Biaya)/Total Biaya x 100\%
ROI $=\quad(5.272 .704 .524-$
$4.333 .574 .045) / 4.333 .574 .045 \times 100 \%$
ROI = 21,67\%

Apabila suatu proyek investasi mempunyai ROI lebih besar dari 0 maka proyek tersebut dapat diterima. Pada perencanaan pengadaan SPI ini nilai ROI nya adalah 0,2167 atau $21,67 \%$. Hal ini berarti perencanaan pengadaan SPI ini dapat diterima dan layak untuk dilakukan karena perencanaan pengadaan SPI ini akan memberikan keuntungan sebesar $21,67 \%$ dari total biaya investasinya.

3. Metode nilai sekarang bersih (net present value), merupakan metode yang memperhatikan nilai waktu dari uang. Kriteria kelayakan penerimaan investasi dengan menggunakan metode NPV yaitu suatu investasi dinyatakan layak jika nilai NPV lebih besar dari nol atau bernilai positif.

Tabel 3 Tabel Perhitungan Net Present Value

\begin{tabular}{r|c|c|r}
\hline Tahun & Cashflow & DF 15\% & \multicolumn{1}{|c}{ Present Value Cash Income } \\
\hline $\mathbf{2 0 2 1}$ & $248,587,210$ & 0.87 & $216,171,437$ \\
\hline $\mathbf{2 0 2 2}$ & $261,016,570$ & 0.76 & $197,354,629$ \\
\hline $\mathbf{2 0 2 3}$ & $274,067,399$ & 0.66 & $180,199,315$ \\
\hline & & Jumlah & $593,725,381$ \\
\hline & & Nilai Investasi & $(11,500,000)$ \\
\hline & & NPV & $582,225,381$ \\
\hline
\end{tabular}

Sumber: Data diolah.

Berdasarkan tabel 4.9.5 diatas, maka perancangan sistem pengendalian internal pada hotel XYZ dapat dikatakan layak karena nilai NPV lebih besar dari nol atau bernilai positif dengan jumlah Rp 582.225.381.

\section{KESIMPULAN}

Perusahaan berskala kecil hingga menengah menghadapi suatu tantangan dalam menerapkan sistem pengendalian internal yang efektif. Hal ini dikarenakan perusahaan berskala kecil hingga menengah memiliki sumber daya terbatas sehingga seringkali mengenyampingkan fungsi pengendalian internal. Hotel XYZ pun tidak luput dari hal tersebut sehingga memunculkan suatu kelemahan dalam penerapan efektivitas pengendalian internal Hotel XYZ jika dibandingkan 
dengan acuan pengendalian internal berdasarkan COSO, yaitu:

1. Pada komponen lingkungan pengendalian, kelemahan yang menonjol terutama adalah kebijakan, peraturan, dan prosedur yang kurang formal, belum didokumentasikan dan tidak dikomunikasikan secara memadai kepada seluruh karyawan.

2. Kelemahan pengendalian yang menonjol pada penaksiran risiko adalah terhadap risiko kecurangan dan fraud.

3. Pada komponen aktivitas pengendalian, kelemahan yang menonjol adalah pengadaan dokumen, pemisahan tugas dan wewenang yang kurang memadai.

4. Pada komponen informasi dan komunikasi, informasi yang diberikan tidak dapat dipertanggungjawabkan karena tidak ada laporan atas persediaan barang guest supplies secara tulisan manual maupun terkomputerisasi.

5. Pada komponen pemantauan, kelemahan pengendalian yang menonjol adalah pemantauan secara periodik atas efektivitas pengendalian intern perusahaan.

Berdasarkan hasil yang dijabarkan pada bab - bab sebelumnya, maka dapat diberikan saran sebagai berikut:

1. Agar hotel XYZ dapat mempertimbangkan dan menerapkan hasil perancangan pengendalian internal persediaan barang guest supplies di hotel XYZ dengan baik dan melakukan review berkala dengan keterlibatan owner yang lebih intens.

2. Jika occupancy perusahaan mengalami peningkatan sampai menyentuh angka diatas $50 \%$ dan posisi keuangan menjadi lebih sehat, maka alangkah lebih baik jika hotel XYZ menambah personil dan mengadakan department purchasing maupun gudang agar tugas accounting menjadi lebih terfokus tehadap aktivitas laporan keuangan saja, dan laporan persediaan barang lebih tertata dan termonitor dengan baik karena disajikan oleh bagian yang benar - benar bertanggung jawab atas persediaan.

\section{DAFTAR PUSTAKA}

Abdul Halim.2012. Akuntansi Sektor Publik. Jakarta: Salemba Empat

Abbas, D. S., \& Hidayat, I. (2021). Enterprise Risk Management, Inventory Intensity, Pre-Tax Foreign Income and Economic Performance: Competitive Advantage as Moderator. LINGUISTICA ANTVERPIENSIA, 3518-3529.

Abbas, D., Ismail, T., Taqi, M., \& Yazid, H. (2021). Determinants of enterprise risk management disclosures: Evidence from insurance industry. Accounting, 7(6), 1331-1338.

Agus Sulastiyono. 2011. Manajemen Penyelenggaraan Hotel: Manajemen Hotel.Bandung: Alfabeta

Anastasia Diana dan Lilis Setiawati. 2011. Sistem Informasi Akuntansi, Perancangan, Prosedur dan Penerapan. Edisi 1. Yogyakarta: Andi Yogyakarta

Hartoni. 2015. Pengembangan Multimedia Interaktif Dalam Media Training Hotel Industri Department Housekeeping. Jakarta: UIB Repository

https://dailyhotels.id/2017/10/caramengetahui-mengetahui-jenis-jenisaset-di-hotel/

Kartikahadi. 2012. Akuntansi keuangan berdasarkan SAK berbasis IFRS. Jakarta: Salemba Empat

Krismiaji. 2015. Sistem Informasi Akuntansi. Edisi Keempat. Yogyakarta: UPP STIM YKPN

Kristanti, Ika Neni. 2019. Pengantar Akuntansi 2. Kebumen: STIE Putra Bangsa

Mulyadi. 2012. Akuntansi biaya. Yogyakarta: UPP Sekolah Tinggi Ilmu Ekonomi YKPN 
Tiara Ratna Biandari, Ludwina Harahap/ Perancangan Sistem Pengendalian Internal Persediaan Barang Guest Supplies Pada Department Housekeeping Di Hotel XYZ

Mulyadi. 2014. Sistem akuntansi (Edisi Ketiga). Jakarta: Salemba Empat

Mulyadi. 2016. Sistem Informasi Akuntansi. Jakarta: Salemba Empat.

Ricky Richard Bua (2020)

Romney, Marshall B. dan Steinbart. 2015.Sistem Informasi Akuntansi, Edisi 13, alihbahasa: Kikin Sakinah Nur Safira dan Novita Puspasari. Salemba Empat: Jakarta

Sari, R.,M. 2013. Pengendalian intern atas pengelolaan persediaan bahan baku pada pabrik gula Modjopanggoong Tulungagung. Jurnal Kompilasi Ilmu
Ekonomi STIE Kesuma Negara Blitar (Vol. 5 No. 2 Desember 2013) Schandl, Annette dan Philip L.Foster. 2019. COSO Internal Control Integrated Framework: An Implementation Guide for the Healthcare Provider Industry. COSO: Crowe.

SK Menteri Perhubungan No. Pm.10/Pw.301/Phb.77

Tjiptono dan Chandra.2011.Pemasaran Jasa. Yogyakarta: Publishing Service

Warren, S.W., et al. 2014. Pengantar akuntansi. Jakarta 